\title{
Identificação médico legal de casos com suspeita: levantamento de perícias do Instituto Médico Legal de São Paulo, na década de 90
}

\section{Legal medical identification of cases with suspicion: survey of perícias of the Legal Medical Institute of São Paulo, in the decade of 90}

\author{
Alessandra Rezzaghi Pettorutti(1), Daniel Romero Muñoz ${ }^{(2)}$, \\ Mario Jorge Tsuchiya ${ }^{(3)}$
}

\begin{abstract}
Pettorutti AR, Muñoz DR, Tsuchiya MJ. Identificação médico-legal de casos com suspeita: levantamento de perícias do Instituto Médico Legal de São Paulo, na década de 90. Saúde, Ética \& Justiça, São Paulo. 2003;8(1/2):18-23.

RESUMO: Os autores realizaram o levantamento de casos de identificação médico legal, com suspeita de ser determinada pessoa, analisados pelo Núcleo de Antropologia do Instituto Médico Legal do Estado de São Paulo, no período de janeiro de 1990 a dezembro de 2000. O levantamento foi realizado através dos laudos médico-legais com o objetivo de obter dados sobre este tipo de perícia, praticamente inexistentes na literatura, bem como verificar os fatores que influenciaram na identificação ou não deste tipo de caso. Resultados: o número total de casos foi de 169, sendo que $125(73,06 \%)$ eram cadáveres putrefeitos ou esqueletizados e $44(26,03 \%)$ carbonizados. Em relação à causa de morte em $93(55,35 \%)$ não foi possível estabelecer a causa de morte e em $39(23,21 \%)$ a morte ocorreu devido a traumatismo crânio encefálico. A identificação resultou positiva em 81 casos $(47,9 \%)$, utilizando-se os métodos odontológicos em 39 casos (60\%), genético em 13 (20\%), antropológico em 9 (13,84\%) e dactiloscópico em 4 casos (6,15\%). Em 88 casos $(52,07 \%)$ não foi possível resultado conclusivo, atribuindo-se a isto a ausência de elementos de confronto, o qual esteve presente em 82 casos (93,18\%). Conclusão: a identificação médico legal depende de elementos de confronto, fornecidos, principalmente pelos familiares, sem os quais não é possível obter um resultado positivo na perícia de identificação médico-legal.
\end{abstract}

DESCRITORES: Medicina legal. Antropologia forense. Identificação de vítimas. Perícia-médica.

(1) Médica Colaboradora do Depto. de Medicina Legal, Ética Médica, Medicina Social e do Trabalho da Faculdade de Medicina da Universidade de São Paulo, Legista do Instituto Médico Legal de São Paulo, Mestre em Medicina pela FMUSP.

(2) Professor livre-docente do Depto. de Medicina Legal, Ética Médica, Medicina Social e do Trabalho da Faculdade de Medicina da Universidade de São Paulo, Legista do Instituto Médico Legal de São Paulo.

(3) Médico Colaborador do Depto. de Medicina Legal, Ética Médica, Medicina Social e do Trabalho da Faculdade de Medicina da Universidade de São Paulo, Legista do Instituto Médico Legal de São Paulo, Bacharel em Direito pela Faculdade de Direito da USP.

Endereço para correspondência: Alessandra R. Pettorutti, Rua Teodoro Sampaio, 115, São Paulo, SP. CEP:05405-000. E-mail: rezzaghi@uol.com.br 


\section{INTRODUÇÃO}

O conceito de identidade pode ser definido como um conjunto de propriedades ou características que tornam alguém essencialmente diferente de todos os demais ${ }^{1}$. A identificação é a determinação da identidade.

A identificação pode ser dividida em duas partes: identificação médica e a policial ou judiciária. A primeira requer conhecimentos especiais de medicina e das várias ciências subsidiárias, e a segunda tem como objetivo principal a caracterização dos delinqüentes em operações rápidas, representada, fundamentalmente pela dactiloscopia, reconhecimento direto e retrato falado $0^{2,3}$.

De acordo com os Códigos de Processo Civil e Penal brasileiros, constituem meios de prova documental, testemunhal e técnica. Desta forma, comprova-se a identidade da pessoa através de documentos ou tecnicamente, através da impressão digital.

Nos cadáveres em que não é possível a realização da dactiloscopia ou do reconhecimento direto, o material da perícia é submetido a identificação médico legal. Esta é subdividida em três partes: física, funcional e psiquica. A identificação física visa estabelecer a espécie animal, raça, sexo, faixa etária e estatural e sinais individuais ${ }^{2,4}$. Estes últimos podem ser traduzidos como malformações, cicatrizes, tatuagens, seqüelas de fraturas, sinais profissionais, exame da arcada dentária e exame de vínculo genético (DNA).

A identificação médico legal é um exame de confronto em que se compara as características individuais obtidas astravés dos familiares com os elementos encontrados no material periciado. $O$ processo de identificação pode resultar na exclusão ou na identificação do indivíduo.

O exame dos arcos dentários é um método que proporciona elementos para uma identificação positiva, e considera que não existem dois arcos dentários idênticos ${ }^{5,6}$.

A identificação depende, no caso de método odontológico, que não exista nenhum fator de exclusão associado ao exame dos arcos dentários que revelam os trabalhos odontológicos realizados durante a vida do individuo ${ }^{8}$, comparados através do exame direto ou de radiografias.
Uma outra forma de proceder à identificação é através do exame de vínculo genético (DNA), o qual consiste na amplificação do material genético, podendo ser realizado através da técnica de reação em cadeia da polimerase (PCR), e posteriormente na comparação da presença dos alelos, através de uma análise estatística ${ }^{9}$. O exame de DNA tem a característica de afastar, ou seja, excluir, a suspeita de ser determinada pessoa ${ }^{10,11}$.

O método de identificação médico legal, realizado no Instituto Médico Legal - Núcleo de Antropologia, nos casos com suspeita, segue o seguinte fluxo:

1. agendar e entrevistar familiares da potencial vítima para coleta de elementos característicos da pessoa procurada e documentações médicohospitalares e odontológicas;

2. após o exame inicial, quando for o caso, diligenciar ao local de encontro do cadáver, com a finalidade de buscar elementos periciais que muitas vezes não estão presentes no cadáver como fragmentos ósseos e dentes;

3. proceder à limpeza do cadáver ou da ossada, possibilitando assim, o estudo antropológico e odontológico, quando são descritas características ósseas e odontológicas que permitirão o confronto com os dados fornecidos pela família ou registrados nas documentações médico-hospitalares e odontológicas da vítima;

4. se resultarem inconclusivas as pesquisas efetuadas, parte do material do biológico recuperado é encaminhado junto com amostra sanguínea para exame de vínculo genético, o qual é realizado junto ao Instituto de Criminalística e teve o inicio de seus trabalhos no ano de $1999^{7}$.

\section{OBJETIVOS}

Levantar, nos casos de identificação médico legal de ossadas e restos humanos com suspeita de serem de determinada pessoa, realizados no IML/ $\mathrm{SP}$, os elementos de interesse médico-legal - tipo de local de encontro, causa da morte, método(s) utilizados - visando, principalmente, estabelecer que fatores que, no nosso meio, contribuem para identificação ou a impossibilitam. 


\section{MATERIAL E MÉTODO}

Foram analisados, retrospectivamente, os casos de perícias de identificação médico legal do Núcleo de Antropologia do Instituto Médico Legal do Estado de São Paulo, no período de janeiro de 1990 a dezembro de 2000.

Todas as informações foram coletadas de laudos médico-legais e das requisições de exame provenientes de Delegacias de Polícia.

Os critérios de inclusão foram a presença de suspeita e a existência de laudo pericial.

Foram excluídos os casos de acidentes de massa.

\section{RESULTADOS}

O número total de casos de perícias identificatórias do Núcleo de Antropologia do Instituto Médico Legal, foi de 1009, no período de janeiro de 1990 a dezembro de 2000. Em 169 (16,7\%) havia suspeita de serem de determinadas pessoas: 125 (73,96\%) eram cadáveres em avançado estado de putrefação ou ossadas e $44(26,03 \%)$ casos de cadáveres carbonizados.

Tabela 1. Material de perícia dos casos com suspeita (IML, 1990-2000).

\begin{tabular}{|c|c|c|}
\hline Material & Freqüência & Porcentagem (\%) \\
\hline \multicolumn{3}{|l|}{ Cadáver putrefeito/ } \\
\hline ossada & 125 & 73,06 \\
\hline Cadáver carbonizado & 44 & 26,03 \\
\hline Total & 169 & 100 \\
\hline
\end{tabular}

Em relação ao gênero, 142 (84,02\%) eram do sexo masculino e 27 (15,97\%) do sexo feminino.

A procedência dos restos humanos, que constavam das requisições de exame emitidas pelas Delegacias de Polícia, foram: via pública, zona rural, estrada/rodovia, residência, carro, avião e leito de rio. Havia também casos advindos de exumação (Tabela 2).
Tabela 2. Locais de encontro dos casos com suspeita (IML, 1990-2000).

\begin{tabular}{lcc}
\hline Origem & Freqüência & Porcentagem (\%) \\
\hline Via Pública & 59 & 34,91 \\
Carro & 26 & 15,38 \\
Exumação & 25 & 14,79 \\
Zona Rural & 24 & 14,20 \\
Estrada/Rodovia & 19 & 11,24 \\
Residência & 11 & 6,50 \\
Avião & 3 & 1,77 \\
Leito de Rio & 2 & 1,18 \\
\hline Total & 169 & 100 \\
\hline
\end{tabular}

Os cadáveres que foram encontrados em carros ou avião estavam, na sua totalidade, carbonizados.

Em relação aos procedentes da residência, quatro casos eram cadáveres carbonizados.

A causa da morte, nos casos em que foi possível estabelecê-la, foram: traumatismo crânioencefálico, carbonização, trauma torácico, trauma tóraco-abdominal, politraumatismos, enforcamento, esgorjamento. Em um dos casos com suspeita, a ossada periciada não era humana (Tabela 3 ).

Tabela 3. Causas da morte dos casos com suspeita (IML, 1990-2000).

\begin{tabular}{lcc}
\hline Causa da Morte & Freqüência & Porcentagem (\%) \\
\hline $\begin{array}{l}\text { Indeterminada } \\
\text { Traumatismo crânio }\end{array}$ & 93 & 55,35 \\
encefálico & 39 & 23,21 \\
Carbonização & 29 & 17,26 \\
Politraumatismo & 2 & 1,19 \\
Trauma Torácico & 2 & 1,19 \\
Trauma toraco- & & \\
abdominal & 1 & 0,60 \\
Enforcamento & 1 & 0,60 \\
Esgorja & 1 & 0,60 \\
\hline Total & 168 & 100 \\
\hline
\end{tabular}

Os principais meios ou mecanismos de morte foram os instrumentos pérfuro-contundentes (projéteis de arma de fogo), contundente, corto-contundente, 
agente físico (calor) e asfixia mecânica (Tabela 4).

Tabela 4. Instrumento, agente e mecanismo de morte nos casos com suspeita e causa morte definida (IML, 1990-2000).

\begin{tabular}{lcc}
\hline $\begin{array}{l}\text { Meio/ Mecanismo } \\
\text { de morte }\end{array}$ & Freqüência & Porcentagem (\%) \\
\hline Perfuro- contundente & 29 & 38,67 \\
Calor & 29 & 38,67 \\
Contundente & 15 & 20,00 \\
Asfixia Mecânica & 1 & 1,33 \\
Corto-contundente & 1 & 1,33 \\
\hline Total & 75 & 100 \\
\hline
\end{tabular}

Dos 169 casos com suspeita, em 81 (47,9\%) obteve-se resultado quanto à identificação (confirmação da suspeita ou exclusão) e em 88 $(52,07 \%)$ casos não foi possível esse tipo de conclusão. Dos casos que obtiveram resultados na identificação, 65 foram identificados (confirmação da suspeita) e 16 excluídos (Tabela 5).

Tabela 5. Casos com resultados na identificação (IML, 1990-2000).

\begin{tabular}{lcc}
\hline Identificação & Freqüência & Porcentagem (\%) \\
\hline Confirmação da & & \\
suspeita & 65 & 80,24 \\
Excluídos & 16 & 19,75 \\
\hline Total & 81 & 100
\end{tabular}

Os métodos de identificação que permitiram obter os resultados supracitados foram os exames antropológico (presença de sinais individualizadores que associados a ausência de elementos excludentes permitiram a identificação), odontológico (confrontação com ficha e/ou com radiografia de arcos dentários), de vínculo genético (DNA) e das impressões digitais (dactiloscopia) - Tabela 6.

Tabela 6. Método de identificação nos casos em que foi confirmada a suspeita (IML, 1990-2000).

\begin{tabular}{lcc}
\hline $\begin{array}{l}\text { Método de } \\
\text { Identificação }\end{array}$ & Freqüência & $\begin{array}{c}\text { Porcentagem } \\
\text { (\%) }\end{array}$ \\
\hline $\begin{array}{l}\text { Exame dos Arcos } \\
\text { Dentários }\end{array}$ & 39 & 60,00 \\
Exame de Vínculo & & 20,00 \\
Genético (DNA) & 13 & 13,84 \\
Exame Antropológico & 9 & 6,15 \\
Dactiloscopia & 4 & 100 \\
Total & 65 & \\
\hline
\end{tabular}

Os casos identificados através da dactiloscopia foram submetidos, na sua totalidade, a tratamento prévio das polpas digitais, tornar possível o exame.

Nos casos, onde foram excluídas as suspeitas, $14(87,5 \%)$ foram através do exame antropológico, observando-se discordância de sexo, faixa etária e estatural, e dois (12,5\%) excluídos através do exame dos arcos dentários.

Nos casos em que não foi possível a identificação médico-legal, observou-se que em 82 $(93,18 \%)$ não houve apresentação pelos familiares de elementos de confronto, pela ausência de informações quanto a estatura e antecedentes médico-hospitalares e/ou odontológicos. Em quatro casos $(4,54 \%)$, representados apenas por fragmentos ósseos, verificou-se a ausência de material para confronto. Em dois $(2,27 \%)$ casos o exame de vínculo genético resultou inconclusivo pela dificuldade de extração e amplificação do DNA genômico.

Tabela 7. Casos sem resultados na identificação médico legal (IML, 1990-2000).

\begin{tabular}{lcc} 
Motivo & Freqüência & Porcentagem (\%) \\
\hline $\begin{array}{l}\text { Ausência de elementos } \\
\text { de confronto }\end{array}$ & 82 & 93,18 \\
$\begin{array}{l}\text { Ausência de material } \\
\text { pericial }\end{array}$ & 4 & 4,54 \\
$\begin{array}{l}\text { Exame de vínculo } \\
\text { Genético inconclusivo }\end{array}$ & 2 & 2,27 \\
\hline Total & 88 & 100 \\
\hline
\end{tabular}

\section{DISCUSSÃO}

Os dados obtidos neste levantamento mostram que dos restos cadavéricos, objeto das perícias de identificação médico-legal, os cadáveres putrefeitos e ossadas são, na maioria das vezes proveniente da via pública (encontrados em locais ermos). Observamos que os cadáveres encontrados no interior de veículos estavam, na sua totalidade, carbonizados.

Em relação ao gênero, observou-se que a maioria $-84,02 \%$ - era do sexo masculino, fato compatível com os dados fornecidos pelo DATASUS no ano de 2001, onde as causas externas foram mais prevalentes no sexo masculino ${ }^{12}$. 
Na maior parte dos casos não foi possível estabelecer a causa da morte, principalmente nas ossadas e cadáveres putrefeitos. Em relação aos carbonizados, observou-se que em 29 casos o médico-legista assinalou a carbonização como causa da morte e o traumatismo crânio-encefálico por instrumento pérfuro-contundente (projétil de arma de fogo) nos outros 15 indivíduos. O esgorjamento (secção do pescoço) decorrente da ação de instrumento corto-contundente), foi verificada em um caso (proveniente de exumação), durante o exame necroscópico. Em um dos casos o material periciado não era humano, e portanto não houve determinação da causa da morte.

Dos casos com suspeita, 47,9\% apresentaram resultado positivo na identificação, isto é, houve confirmação ou exclusão da suspeita. O método mais freqüentemente utilizado nas confirmações foi o exame dos arcos dentários (60\%), seguido do exame de DNA (20\%). Em $13,84 \%$ dos casos, os corpos apresen-tavam sinais individualizadores que permitiram estabelecer, com segurança, a identidade.

Nos casos em que foi utilizada a dactiloscopia, as polpas digitais tiveram que ser tratadas previamente, na sua totalidade com hidratação da epiderme e derme, para proporcionar condições para a averiguação de suas características.

Em 52,07\% dos casos não foi possível a identificação, observando-se que o motivo mais freqüente foi a ausência de elementos de confronto, seja pela falta de informações fidedignas (por exemplo, estatura e sinais peculiares), ou pela ausência de documentação médico-odontológica. Em quatro casos havia somente pequenos fragmentos ósseos, não tendo sido possível a identificação.

Em relação ao exame de DNA, o resultou foi positivo em 13 casos e inconclusivo em quatro, sendo que nestes últimos as dificuldades de extração e amplificação do DNA genômico inviabilizaram a realização do confronto. Salienta-se que o exame de DNA começou a ser realizado no ano de $1999^{7}$, explicando-se a baixa freqüência deste método de identificação, neste levantamento.

\section{CONCLUSÃO}

O exame de identificação consiste na comparação das características individuais, obtidas através dos familiares, com os elementos encontrados no material periciado. Para tanto, é fundamental o conhecimento das características da pessoa, assim como seus antecedentes médicos e odontológicos.

$\mathrm{Na}$ literatura médica, nota-se uma acentuada escassez de trabalhos abordando os fatores que influenciam na identificação da ossada e restos humanos. Neste estudo observou-se que a impossibilidade de identificação decorreu na maioria dos casos da ausência de dados fidedignos fornecidos pelos familiares e da inexistência de documentação médica e odontológica.

Pettorutti AR, Muñoz DR, Tsuchiya MJ. Legal medical identification of cases with suspicion: survey of perícias of the Legal Medical Institute of São Paulo, in the decade of 90. Saúde, Ética \& Justiça, São Paulo. 2003;8(1/ 2):18-23.

ABSTRACT: The authors had carried through the survey of cases of legal medical identification, with suspicion of being determined person, analyzed for the Nucleus of Anthropology of the Legal Medical Institute of the State of São Paulo, in the period of January of 1990 the December of 2000 . The survey was carried through the legal findings medical with the objective to get given on this type of skill, practically inexistent in literature, as well as verifying the factors that had influenced in the identification or not of this type of case. Results: the total number of cases was of 169 , being that $125(73,06 \%)$ were bodies in decomposition or skeletons and 44 $(26,03 \%)$ carbonized. In relation to the cause of death in $93(55,35 \%)$ it was not possible to establish the death cause and in $39(23,21 \%)$ the death occurred due to brain injury. The identification resulted positive in 81 cases $(47,9 \%)$, using the odontologic methods in 39 cases $(60 \%)$, genetic in $13(20 \%)$, anthropologic in $9(13,84 \%)$ and fingerprints in 4 cases $(6,15 \%)$. In 88 cases $(52,07 \%)$ it was not possible conclusive result, attributing this to it the absence of confrontation elements, which were present in 82 cases $(93,18 \%)$. Conclusion: the legal medical identification depends on confrontation elements, supplied, mainly for the familiar ones, without which it is not possible to get a positive result in the skill of legal medical identification.

KEY WORDS: Forensic medicine. Forensic anthropology. Victims identification.Medical inspection. 


\section{REFERÊNCIAS}

1. Maranhão OR. Curso básico de medicina legal. São Paulo: Malheiros; 1999.

2. Carvalho HV. Compêndio de medicina legal. São Paulo: Martins; 1973.

3. França GV. Medicina legal. Rio de Janeiro: Guanabara Koogan; 1998.

4. Arbenz GO. Medicina legal e antropologia forense. Rio de Janeiro: Atheneu; 1988.

5. Silva M. Compendio de odontologia legal. São Paulo: Medsi; 1997.

6. Clark DH. An analysis of the value of forensic odontology in ten mass disasters. Int Dent $\mathrm{J}$, Bristol. 1994;44(3):241-50.

7. Resolução SSP-194, 02/06/1999. Diário Oficial do Estado de São Paulo, São Paulo. 02 jun. 1999.

8. Gomes EM. Aspectos de interesse odontolegal observados nas perícias de identificação humana realizados no Instituto Médico Legal de São Paulo nos anos de 1999 a 2000 [dissertação]. São Paulo: Faculdade de Odontologia, Universidade de São Paulo; 2000.

9. Eisenstein $\mathrm{BI}$. The polymerase chain reaction. $\mathrm{N}$ Engl J Med. 1990;322:178-82.

10. Nishimi RY. From the congressional office of technology assessment. JAMA. 1991;264:480-500.

11. Muñoz DR. Perícia médico-legal nos desastres de massa: análise metodológica e planejamento para a identificação de vítimas de acidente aéreo no Brasil [Tese Livre-docência]. São Paulo: Faculdade de Medicina, Universidade de São Paulo; 1999.

12. Departamento de Informática do Sistema Único de Saúde. Disponível em: http://datasus.gov.br. 